i.e.

$$
\begin{aligned}
d & =f b / K_{\mathrm{PF}} \\
& =\left(f p / K_{\mathrm{P}} K_{\mathrm{PF}}\right) a K_{m} / s .
\end{aligned}
$$

Substituting in (6) the values for $b, c$ and $d$ obtained in Eqns. (7)-(9), we find

$$
a=e /\left\{1+\left(K_{m} / s\right)\left(1+p / K_{\mathrm{P}}+f / K_{\mathrm{F}}+f p / K_{\mathrm{P}} K_{\mathrm{PF}}\right)\right\} .
$$

The rate of the reaction,

i.e.

$$
v=\mathrm{d} s / \mathrm{d} t=k_{3}^{\prime} a,
$$

$$
v=k_{8}^{\prime} e /\left\{1+\left(K_{m} / 8\right)\left(1+p / K_{\mathrm{P}}+f / K_{\mathrm{F}}+f p / K_{\mathrm{P}} K_{\mathrm{PF}}\right)\right\} .
$$

When $s=\infty, \quad v=V=k_{3}{ }^{\prime} e$,

i.e.

$$
v=V /\left\{1+\left(K_{m} / s\right)\left(1+p / K_{\mathrm{P}}+f / K_{\mathrm{F}}+f p / K_{\mathrm{P}} K_{\mathrm{PF}}\right)\right\},
$$

or $V / v=1+\left(K_{m} / s\right)\left(1+p / K_{\mathrm{P}}+f / K_{\mathrm{F}}+f p / K_{\mathrm{P}} K_{\mathrm{PF}}\right)$.

Expressing $K_{m}$ as rate constants,

$$
\begin{aligned}
V / v=1 & +\left(k_{2}+k_{3}{ }^{\prime}\right) \\
\times\left(1+p / K_{\mathrm{P}}+f / K_{\mathrm{F}}+f p / K_{\mathrm{P}} K_{\mathrm{PF}}\right) / k_{1} s & \\
=1 & +\left(k_{2} / k_{1} s\right)\left(1+p / K_{\mathrm{P}}+f / K_{\mathrm{F}}+f p / K_{\mathrm{P}} K_{\mathrm{PF}}\right) \\
& +\left(V / k_{1} s e\right)\left(1+p / K_{\mathrm{P}}+f / K_{\mathrm{F}}+f p / K_{\mathrm{P}} K_{\mathrm{PF}}\right),
\end{aligned}
$$

i.e. at fixed $p, f$ and $s, V / v$ will be a linear function of $V$.

When $V / v=1$,

$$
\begin{aligned}
\left(k_{2} / k_{1} s\right) & \left(1+p / K_{\mathrm{P}}+f / K_{\mathrm{F}}+f p / K_{\mathrm{P}} K_{\mathrm{PF}}\right) \\
=-\left(V / k_{1} s e\right)\left(1+p / K_{\mathrm{P}}+f / K_{\mathrm{F}}+f p / K_{\mathrm{P}} K_{\mathrm{PF}}\right), & \\
\text { i.e. } & -V=k_{2} e,
\end{aligned}
$$

i.e. the extrapolated value of $V$ obtained by continuing the straight line obtained by plotting $V / v$ against $V$ to the value $V / v=1$ will be equal to $-k_{2} e$.

Returning to Eqn. (5),

i.e.

$$
\begin{aligned}
& d / c p=1 / K_{\mathrm{FP}}, \\
d= & c p / K_{\mathrm{FP}} \\
= & \left(p f / K_{\mathrm{F}} K_{\mathrm{FP}}\right) a K_{m} / s,
\end{aligned}
$$

substituting the value for $c$, given by Eqn. (8). But, by Eqn. (9),

$$
\begin{gathered}
d=\left(p f / K_{\mathrm{P}} K_{\mathrm{PF}}\right) a K_{m} / s . \\
K_{\mathrm{F}} K_{\mathrm{FP}}=K_{\mathrm{P}} K_{\mathrm{PF}} .
\end{gathered}
$$

\title{
The Action of Thrombin on Fibrinogen
}

\author{
By L. LORAND AND W. R. MIDDLEBROOK \\ Department of Biomolecular Structure, University of Leeds
}

(Received 31 January 1952)

A number of workers in the field of blood coagulation (Schmidt, 1895; Mellanby, 1908; Hammarsten, 1914; Nolf, 1938) have sought to explain the conversion of fibrinogen to fibrin in terms of a proteolytic change. Though this concept has been contradicted recently (Jaques, 1938; Astrup, 1950), the fact that certain proteases, e.g. papain (Eagle \& Harris, 1937) and some snake venoms (Eagle, 1937) can bring about clotting served to uphold the idea. However useful the information gained by analogy from other enzymes, direct proof was necessary to show that thrombin acts in a similar manner. It was therefore desirable to undertake a systematic comparison of the free amino groups of both fibrinogen and fibrin. Sanger's (1945) method was used because of its high sensitivity and usefulness in the identification of the amino-acids involved.

A preliminary account of part of this work has already been published in conjunction with Dr K. Bailey and Mr F. R. Bettelheim (Bailey, Bettelheim, Lorand \& Middlebrook, 1951), who worked independently.

\section{EXPERIMENTAL}

\section{Materials}

Fibrinogen. Since there is no real criterion of purity for fibrinogen, several methods of preparation were tried which were known to produce material of clottability exceeding $90 \%$. In most cases fresh bovine plasma collected in $0.2 \%$ (w/v) sodium oxalate was used as the source of fibrinogen.

(I) Bovine plasma was precipitated with 0.25 saturated $\left(\mathrm{NH}_{4}\right)_{2} \mathrm{SO}_{4}$, the precipitate was centrifuged and redissolved in one-third of the original plasma volume of $0.9 \%(w / v)$ $\mathrm{NaCl}$ containing $0.2 \%(\mathrm{w} / \mathrm{v})$ sodium oxalate, and the solution was then filtered. The precipitation with 0.25 saturated $\left(\mathrm{NH}_{4}\right)_{2} \mathrm{SO}_{4}$ was repeated three times, and the final precipitate was dissolved in $0.9 \%(\mathrm{w} / \mathrm{v}) \mathrm{NaCl}$ and dialysed at $2^{\circ}$ against a similar solution for $48 \mathrm{hr}$. It was then filtered through paper pulp which had been washed with $0.9 \%(\mathrm{w} / \mathrm{v})$ $\mathrm{NaCl}$.

(II) The first precipitation with $\left(\mathrm{NH}_{4}\right)_{2} \mathrm{SO}_{4}$ was the same as in the previous case; the separated precipitate was dissolved in one-third of the original plasma volume of $0.9 \%$ $(\mathrm{w} / \mathrm{v}) \mathrm{NaCl}$ and was filtered through paper pulp. The solution was then cooled to $0^{\circ}$ and diluted to 10 vol. with cold distilled water. The fibrinogen was precipitated by the addition 
of $\mathrm{N}$-acetic acid to $\mathrm{pH} 5 \cdot 5$, centrifuged and redissolved in one-tenth of the original plasma volume of $0.9 \%(w / v) ~ \mathrm{NaCl}$ and neutralized by the addition of $\mathrm{NH}_{4} \mathrm{OH}$ to $\mathrm{pH} 7 \cdot 0-7 \cdot 5$ (Bagdy's (1948) method: personal communication).

(III) Bovine fraction I (Armour) (1 g.) was dissolved in $100 \mathrm{ml}$. 0.05 M-phosphate buffer $\left(\mathrm{KH}_{2} \mathrm{PO}_{4}: \mathrm{Na}_{2} \mathrm{HPO}_{4}=2: 1\right)$. The solution was left in a refrigerator overnight and then filtered through paper pulp. One-third of saturated $\left(\mathrm{NH}_{4}\right)_{2} \mathrm{SO}_{4}$ was added to the filtrate and the precipitate was centrifuged, redissolved in $40 \mathrm{ml} .0 \cdot 3 \mathrm{M}-\mathrm{KCl}$ solution made slightly alkaline ( $\mathrm{pH} \mathrm{7.5)}$ by the addition of $\mathrm{NaHCO}_{3}$, then dialysed in the cold for $60 \mathrm{hr}$. against $0 \cdot 2 \mathrm{M}-\mathrm{KCl}$. The freshly dialysed solution was finally filtered through a fine paper (Laki, 1951).

(IV) A sample of highly pure fibrinogen was made available by the courtesy of Prof. Seegers (no. 501020).

Thrombin. Hoffmann-La Roche and Seegers' purest thrombin preparations, known to be non-fibrinolytic, were used. Both were obtained as gifts.

Fibrin. This was isolated from any unchanged fibrinogen and from occlusions in the clot network by means of its solubility in urea (Lorand, 1948, 1950). The samples of fibrinogen were clotted with minute amounts of thrombin, the clot was dissolved in $30 \%(w / v)$ urea, and the solution was then poured into a large volume of $0.9 \%(w / v) ~ \mathrm{NaCl}$ solution, whereupon the fibrin separated out leaving any occluded material in solution. It is necessary to reduce the concentration of urea as much as possible, and certainly below $0.5 \%(w / v)$. The precipitated fibrin was washed thoroughly first with $0.9 \%(w / v) ~ N a C l$ solution, then with water. (This method of recovering fibrin forms the basis of a newly devised clotting test; Lorand, 1951 a.)

The clot system, consisting of fibrin and clot liquor, was also examined. Light's 1-fluoro-2:4-dinitrobenzene (FDNB) was used, and all the other reagents were of analytical purity.

\section{Methods}

Treatment with FDNB. The proteins were treated with FDNB under the conditions recommended by Sanger (1945), and the reaction was carried out at room temperature for 16-24 hr. This ensured complete penetration and reaction of FDNB even in the case of fibrin and the whole clot system. The treated proteins were washed with water, ethanol and ether and were dried at $110^{\circ}$.

Hydrolysis and separation of dinitrophenylamino-acids (DNP-acids). About $200 \mathrm{mg}$. of the treated proteins were hydrolysed under reflux in $20 \mathrm{ml} .5 \cdot 7 \mathrm{~N}-\mathrm{HCl}$. When DNPglycine was being investigated, a compromise had to be effected between liberation and hydrolytic breakdown of this labile compound; thus the times of hydrolysis were set at 6,8 and $12 \mathrm{hr}$. In the case of more stable DNP-acids, 24 and $48 \mathrm{hr}$. were chosen for times of hydrolysis.

The hydrolysate was shaken with peroxide-free ether and the DNP-acids which were ether-soluble were examined first by Sanger's method (1945). Extensive use was made of the buffered columns recommended by Middlebrook (1949, 1950, 1951). Columns were usually made from $2 \mathrm{~g}$. of silicagel by using $0.5 \mathrm{ml}$. of the stationary phase per $1 \mathrm{~g}$. of silica. The DNP-acids were identified by measuring their $R$ values on various columns in conjunction with various solvents, and comparing with the $R$ values given by authentic samples of standard DNP-acids on the same columns.

The ether-soluble portion was estimated by evaporating the solution to dryness in a flask, and the residue was dis- solved in a small amount of $\mathrm{CHCl}_{3}$ and run on a $\mathrm{pH} 6.0$ column with $\mathrm{CHCl}_{3}$. The fast-moving decomposition products, including 2:4-dinitroaniline, were removed, but all the DNP-acids remained at the top of the column. The flask was rinsed with a small amount of ether, which was transferred to the column and the mobile solvent was changed to ether. Several bands were formed with $R$ values that allowed the separation of a number of DNP-acids, e.g. bis-DNP-tyrosine was collected in the fast band, DNP. glycine moved with $R=0.5$ and DNP-glutamic acid with $R=0 \cdot 08$. When DNP-threonine, -serine and -aspartic acid were present, they gave $R$ values of $0.3,0.2$ and 0.02 , respectively. In general, further identification and separation of the collected bands was carried out on other columns suitable for their characterization. The bis-DNP-tyrosine was passed through an unbuffered column with $\mathrm{CHCl}_{3}$ $(R=0 \cdot 4)$, DNP-glycine was run on an unbuffered column with $\mathrm{CHCl}_{3}(R=0 \cdot 2)$, and DNP-glutamic acid with $1 \%(\mathrm{v} / \mathrm{v})$ butanol- $\mathrm{CHCl}_{3}(R=0 \cdot 1)$ on an unbuffered column.

The material remaining in the acid phase was estimated by drying down a portion of the ether-extracted hydrolysate, then taking it up in $30 \%(\mathrm{v} / \mathrm{v})$ butanol- $\mathrm{CHCl}_{3}$ and passing it through a silica-gel column with water as the stationary phase. In the experiments with fibrinogen and fibrin, only one band could be observed on this column corresponding to $\epsilon$ - $N$-DNP-lysine $(R=0 \cdot 14)$.

Estimation of DNP-acids. The separated DNP-acids were made up to a volume of $10 \mathrm{ml}$. in the appropriate solvent and estimated by using a Beckman ultraviolet spectrophotometer. $\epsilon-N-D N P-l y s i n e$ was measured in a solution of $\mathrm{N}-\mathrm{HCl}$, and the ether-soluble DNP-acids in a solution of $1 \%$ $(\mathbf{w} / \mathbf{v}) \mathrm{NaHCO}_{3}$, and the optical densities were compared with calibrated values of standard DNP-acids. Readings of the ether-soluble DNP-acids were taken at 350 and $360 \mathrm{~m} \mu$., where they show maximal absorption; $\epsilon-N$-DNP-lysine, however, was read at $390 \mathrm{~m} \mu$. as recommended by Sanger (1949). At concentrations less than $60 \mu \mathrm{M}$ absorptions of the DNP-acids investigated obey Beer's law and measurements were taken within this limit of concentration.

Rate of decomposition of DNP-acids. By estimating the free DNP-acids after hydrolysing, for different lengths of time, portions of the same batch of treated protein, it is possible to measure the decomposition rates of the DNP. acids (Middlebrook, 1950, 1951). The general procedure for separating the DNP-acids was exactly the same as described above. Table 1 shows the hydrolytic breakdown of the DNP-acids derived from fibrinogen and fibrin. It seems that DNP-acids which are relatively stable in one system may be more labile in another. While the rate of decomposition found for DNP-glycine is close to that given by Sanger for insulin (Sanger, 1945) and by Middlebrook for wool (Middlebrook, 1950, 1951), the DNP-glutamic acid proved to be considerably more stable in the present case than in those reported by Porter \& Sanger (1948) and by Middlebrook $(1950,1951)$. In view of the small amount of DNP-aspartic acid obtained from the treated fibrinogen the destruction rate of this acid was not determined, but the correction factor of Porter \& Sanger (1948) was used.

The yields of DNP-glycine, corrected for loss by hydrolysis, were found to be the same after 8 and $12 \mathrm{hr}$. hydrolysis of the treated fibrin, but lower after only $6 \mathrm{hr}$. hydrolysis. Accordingly, in accurate determinations of the labile DNP. glycine, $8 \mathrm{hr}$. was chosen for hydrolysis in order to compromise between reasonable breakdown and as complete hydrolysis as possible. 
Amide $\mathrm{N}$ determination. It was necessary to know the protein content of the treated fibrinogen and fibrin, and this was computed indirectly by estimating the amide $N$ of the treated protein and comparing it with the value obtained for the untreated protein (Sanger, 1945). A mild hydrolysis was

Table 1. Hydrolytic breakdown of DNP-acids by boiling in $5 \cdot 7 \mathrm{~N}-\mathrm{HCl}$

$\begin{array}{lcc}\text { Amino-acid derivative } & \begin{array}{c}\text { Time of } \\ \text { hydrolysis } \\ (\text { hr. })\end{array} & \begin{array}{c}\text { Amount } \\ \text { unchanged } \\ (\%)\end{array} \\ \text { DNP-glutamic acid } & 24 & 80 \\ & 24 & 81 \\ \text { DNP-glycine } & 24 & 85 \\ & 4 & 56 \\ \text { G-N-DNP-lysine } & 16 & 21 \\ \text { Bis-DNP-tyrosine } & 24 & 93 \\ & 24 & 94 \\ & 16 & 81 \\ & 24 & 67 \\ & 40 & 55 \\ & 40 & 59\end{array}$

used with $2 \mathrm{~N}-\mathrm{HCl}$ for $4 \mathrm{hr}$., and after neutralization the liberated $\mathrm{NH}_{3}$ was estimated in the micro-Kjeldahl apparatus as recommended by Sanger (1945). The amide $N$ was found to be $1.30 \%$ for fibrinogen and $1.31 \%$ for fibrin, in close agreement with the values given by Bailey (1944). residue and in very minute proportion. Table 2 illustrates the $N$-terminal groups probably related to impurities in the various fibrinogen preparations examined.

Fibrin. The samples of purified fibrin contained glycine and tyrosine $N$-terminal groups and in all cases were free from traces of other end groups.

\author{
Table 2. N-Terminal groups probably \\ related to impurities \\ Fibrinogen \\ sample \\ I Traces of glycine, serine, threonine, aspartic acid \\ II Traces of glycine, serine, threonine, aspartic acid \\ III Traces of threonine, aspartic acid \\ IV Very minute traces of aspartic acid
}

The clot system. To obtain strict comparisons and also to make equal allowance for possible impurities, experiments in parallel were undertaken with fibrinogen and with the whole fibrin-plussupernatant system obtained from it. The clot was found always to contain a considerable number of $N$-terminal groups of glycine, whereas none or only very few were found in fibrinogen. Also the number of glutamic acid $N$-terminal groups in the clotted

Table 3. Estimated number of moles of $\alpha$-DNP-acids per 450000 unit of protein, after correction for hydrolytic breakdown (time of hydrolysis in hours in brackets)

(Values in this table were derived from the same batch of fibrinogen. Where more than one value is given, these were obtained from different hydrolysates.)

$\begin{array}{lcccc} & \alpha \text {-DNP-aspartic acid } & \alpha \text {-DNP-glutamic acid } & \alpha \text {-DNP-glycine } & \text { Bis-DNP-tyrosine } \\ \text { Fibrinogen IV } & 0.15(24) & 0.9(24) & \text { Absent (8) } & 2 \cdot 0(8) \\ & & 0.9(24) & & 2.0(48) \\ \text { Clot } & \text { Absent (12) } & \text { Traces (12) } & 4.0(8) & \begin{array}{c}\text { Present, not } \\ \text { estimated }\end{array} \\ & & & 4 \cdot 1(12) & (24) \\ \text { Purified fibrin } & \text { Absent (24) } & & & 2 \cdot 0(8) \\ & & & & 2 \cdot 1(24)\end{array}$

\section{RESULTS}

Fibrinogen. The different preparations examined for $N$-terminal groups gave essentially the same results in that glutamic acid and tyrosine (the latter was first observed by Bailey, 1951) were the chief terminal residues in all of them. In some preparations variable traces of glycine end groups were found, but these may be ascribed either to impurities or, more probably, to traces of fibrin (see below). In most of the samples listed, other $N$ terminal groups as well, including those of aspartic acid, serine and threonine, were detected in relatively small and varying proportions. One may safely assume that the presence of the last-named is due to impurities. In one of the purest preparations of fibrinogen, apart from glutamic acid and tyrosine, only aspartic acid could be found as an $N$-terminal
Table 4. Lysine content derived from the $\epsilon-N-D N P$ lysine estimations after $24 \mathrm{hr}$. hydrolysis

(Values in this table were derived from the same batch of fibrinogen, preparation IV. The two values given for fibrinogen were obtained from one hydrolysate.)

\begin{tabular}{|c|c|c|c|}
\hline & $\begin{array}{l}\text { Lysine } / 100 \mathrm{~g} . \\
\text { protein } \\
\text { (g.) }\end{array}$ & $\begin{array}{l}\text { Lysine } N \\
\text { as \% of } \\
\text { total } \\
\text { protein } N\end{array}$ & $\begin{array}{l}\text { Moles lysine/ } \\
450000 \text { unit } \\
\text { of protein }\end{array}$ \\
\hline Fibrinogen & $\begin{array}{l}6 \cdot 32 \\
6 \cdot 36\end{array}$ & $\begin{array}{l}7 \cdot 17 \\
7 \cdot 22\end{array}$ & $\begin{array}{l}195 \\
196\end{array}$ \\
\hline Clot & $6 \cdot 27$ & $7 \cdot 12$ & 193 \\
\hline Purified fibrin & $6 \cdot 68$ & $7 \cdot 58$ & 206 \\
\hline
\end{tabular}

protein was greatly reduced as compared with that of the unclotted material.

The results of the threefold approach outlined above are summarized in Tables 3 and 4. 


\section{DISCUSSION}

It is concluded from these results that fibrinogen contains $N$-terminal groups of glutamic acid and tyrosine, while fibrin has $N$-terminal groups of glycine and tyrosine. The quantitative values indicate that in a unit weight of 450000 , fibrinogen has one glutamic acid and two tyrosine $N$-terminal residues (thus such a unit possesses three open peptide chains). It is believed that the small amount of terminal aspartic acid is due to impurities in the fibrinogen samples, since only one aspartic acid $N$-terminal group would be present in 5-10 times the unit weight chosen. A value of 450000 is in close agreement with published values for the molecular weight of fibrinogen (Edsall, Foster \& Scheinberg, 1947). The same unit of fibrin ends in two tyrosine and presumably four glycine $N$. terminal residues.

An important conclusion can be drawn from these results with regard to changes that occur during the fibrinogen-fibrin transformation, namely that $\alpha$-amino groups of glycine are liberated, possibly by the fission of glycyl-peptide bonds within the molecule. Such a change is a strong argument in favour of the proteolytic nature of the clotting mechanism. Bailey \& Bettelheim (Bailey et al. 1951) have shown, in addition, that the action of thrombin seems specific for fibrinogen, since incubation of proteins such as ovalbumin and myosin with thrombin does not result in the liberation of new $N$-terminal groups; they have also proved that denaturation of fibrinogen does not bring about the appearance of glycine end groups. It is necessary to point out that our results and conclusions refer only to bovine fibrinogen; the structure of fibrinogen and the enzymic changes which take place on clotting may be species specific. Also, though the action of papain and proteolytic snake venoms on fibrinogen is known to result in clot formation, it does not follow that the changes at the molecular level are identical with those brought about by thrombin.

It can be seen from the results that the glutamic acid $N$-terminal residues present in fibrinogen could not be found by the FDNB method in the resulting fibrin. It was reasonable to suppose that the 'disappearance' of glutamic acid end groups was due to a splitting-off of a portion of the fibrinogen molecule which was removed as an $\alpha$-DNP-glutamylpeptide during washing after the FDNB treatment. Indeed, this assumption prompted the investigations which led to the discovery of fibrino-peptide (Lorand, 1951 $a, b, 1952$ ).

Within the limits of experimental error fibrinogen and fibrin contain the same number of free $\epsilon-N$ groups of lysine as revealed by the FDNB method. Our values are somewhat lower than those found by Bailey (1951), who arrived at interesting conclusions with regard to the possible role of unreactive lysine side chains in the aggregation of fibrin particles.

\section{SUMMARY}

1. Bovine fibrinogen and fibrin were treated by the dinitrophenyl-method and the $N$-terminal residues determined.

2. In the fibrinogen molecule two chains end in tyrosine and one in glutamic acid. The same unit weight of fibrin has two $N$-terminal residues of tyrosine and four of glycine.

3. It was shown that the action of thrombin on fibrinogen results in the fission of glycyl-peptide bonds within the molecule, with the formation of fibrin and, it is suggested, the simultaneous removal of $N$-terminal residues of glutamic acid as part of a peptide.

4. Fibrinogen and fibrin contain the same number of free $\epsilon-N$ groups of lysine.

We wish to express our thanks to Prof. W. T. Astbury, F.R.S., for his interest and encouragement.

\section{REFERENCES}

Astrup, T. (1950). Advanc. Enzymol. 10, 1.

Bagdy, D. (1948). Personal communication.

Bailey, K. (1944). Advanc. Protein Chem. 1, 289.

Bailey, K. (1951). Biochem. J. 49, 23.

Bailey, K., Bettelheim, F. R., Lorand, L. \& Middlebrook, W. R. (1951). Nature, Lond., 167, 233.

Eagle, H. (1937). J. exp. Med. 65, 613.

Eagle, H. \& Harris, T. N. (1937). J. gen. Physiol. 89, 545 . Edsall, J. T., Foster, J. F. \& Scheinberg, H. (1947). J. Amer:chem. Soc. 69, 2731.

Hammarsten, O. (1914). A Textbook of Physiological Chemistry, 7th English ed. New York: Wiley.

Jaques, L. B. (1938). Biochem. J. 32, 1181.

Laki, K. (1951). Arch. Biochem. Biophys. 32, 317.

Lorand, L. (1948). Hung. Acta physiol. 1, 192.
Lorand, L. (1950). Nature, Lond., 166, 694.

Lorand, L. (1951 a). Thesis. University of Leeds.

Lowind, L. (1951 b). Nature, Lond., 167, 992.

Eotand, L. (1952). Biochem. J. 52, 200.

Mellanby, J. (1908). J. Physiol. 38, 28.

Midd pbrook, W. R. (1949). Nature, Lond., 164, 501.

Miduebrook, W. R. (1950). Thesis. University of Leeds.

tiddlebrook, W. R. (1951). Biochim. Biophys. Acta, 7, 547.

Nolf, P. (1938). Medicine, 17, 381.

Porter, R. R. \& Sanger, F. (1948). Biochem. J. 42, 287.

Sanger, F. (1945). Biochem. J. 39, 507.

Sanger, F. (1949). Biochem. J. 45, 563.

Schmidt, A. (1895). Weitere Beiträge zur Blutlehre. Wiesbaden: Bergmann. 